\title{
GT198 Expression Defines Mutant Tumor Stroma in Human Breast Cancer
}

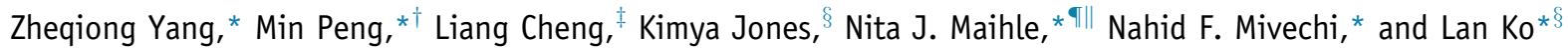

From the Cancer Center,* and the Departments of Pathology, ${ }^{\S}$ Biochemistry and Molecular Biology, " and Obstetrics Gynecology, "Medical College of Georgia, Augusta University, Augusta, Georgia; the Oncology Center, ${ }^{\dagger}$ Renmin Hospital of Wuhan University, Wuhan, China; and the Department of Pathology, ${ }^{\ddagger}$ Indiana University School of Medicine, Indianapolis, Indiana

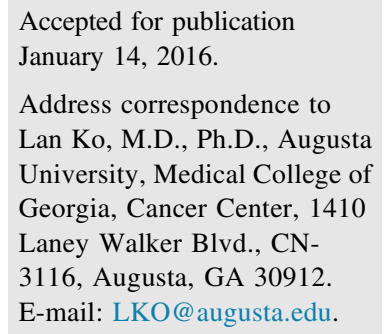

Address correspondence to Lan Ko, M.D., Ph.D., Augusta University, Medical College of Georgia, Cancer Center, 1410 Laney Walker Blvd., CN3116, Augusta, GA 30912. E-mail: LKO@augusta.edu.

\begin{abstract}
Human breast cancer precursor cells remain to be elucidated. Using breast cancer gene product GT198 (PSMC3IP; alias TBPIP or Hop2) as a unique marker, we revealed the cellular identities of GT198 mutant cells in human breast tumor stroma. GT198 is a steroid hormone receptor coactivator and a crucial factor in DNA repair. Germline mutations in GT198 are present in breast and ovarian cancer families. Somatic mutations in GT198 are present in ovarian tumor stromal cells. Herein, we show that human breast tumor stromal cells carry GT198 somatic mutations and express cytoplasmic GT198 protein. $\mathrm{GT}_{198}{ }^{+}$stromal cells share vascular smooth muscle cell origin, including myoepithelial cells, adipocytes, capillary pericytes, and stromal fibroblasts. Frequent GT198 mutations are associated with GT198 ${ }^{+}$tumor stroma but not with $\mathrm{GT}_{198^{-}}$tumor cells. GT198 ${ }^{+}$progenitor cells are mostly capillary pericytes. When tested in cultured cells, mutant GT198 induces vascular endothelial growth factor promoter, and potentially promotes angiogenesis and adipogenesis. Our results suggest that multiple lineages of breast tumor stromal cells are mutated in GT198. These findings imply the presence of mutant progenitors, whereas their descendants, carrying the same GT198 mutations, are collectively responsible for forming breast tumor microenvironment. GT198 expression is, therefore, a specific marker of mutant breast tumor stroma and has the potential to facilitate diagnosis and targeted treatment of human breast cancer. (Am J Pathol 2016, 186: 1340-1350; http://dx.doi.org/10.1016/j.ajpath.2016.01.006)
\end{abstract}

Breast tumor stroma provides a microenvironment that stimulates the growth of luminal epithelial tumor cells. Several breast stromal components have been shown to be critical in breast cancer initiation. Myoepithelial cells juxtaposed between the surrounding stroma and luminal epithelium are essential for the integrity of normal breast tissue and for the maintenance of ductal architecture, including cell polarity. ${ }^{1-3}$ Myoepithelial cells are steroid hormone responsive, $1,4,5$ mediating signals required for normal ductal epithelium growth and differentiation. ${ }^{1}$ In early-stage breast cancer, myoepithelial cells serve as endogenous tumor suppressors and their loss is accompanied by disrupted ductal structure and disorganized luminal epithelial cells. ${ }^{6-8}$

Pericytes are another critical component in cancer initiation because pericytes envelop the endothelial lining of vessels and contain multipotent stem cells or progenitors. ${ }^{9-11}$ Pericytes are also central to tumor angiogenesis. ${ }^{12,13}$ When altered, pericytes potentially produce multiple lineages of altered stromal cells, including adipocytes ${ }^{10,14}$ and fibroblasts. ${ }^{15,16}$ Adipocytes produce endocrine, inflammatory, and angiogenic factors that further contribute to the tissue microenvironment. ${ }^{17,18}$ Increased fatty acid synthesis, stimulated by up-regulated lipogenic genes, is considered one of the hallmarks of cancer. ${ }^{19,20}$ However, the relationships among these stromal components are not fully understood, and direct evidence supporting a stromal component in breast cancer initiation is still needed. In particular, the specific genetic defects in breast cancer stroma driving cancer initiation are largely unclear.

In this study, using the breast and ovarian cancer gene product GT198 (gene symbol PSMC3IP, encodes GT198,

Supported in part by the Georgia Cancer Coalition Distinguished Cancer Scholar Award (L.K.), the Natural Science Foundations in China 81102024 and in Hubei Province 2013CFB234 (M.P.), NIH grants CA062130 and CA132640 (N.F.M.), the Susan G. Komen Foundation grant KG111460 (N.J.M.), and Medical College of Georgia Development Funds (N.J.M.).

Disclosures: L.K. is inventor of and holds patents for GT198 as a biomarker in breast cancer diagnosis and drug screening. No financial agreement or licensing has been involved. 
alias TBPIP or Hop2) as a specific marker, we have identified mutant cell populations in human breast tumor stroma that harbor GT198 somatic mutations. GT198 protein is a steroid hormone receptor coactivator regulating estrogen, androgen, glucocorticoid, and progesterone receptor (PR)-mediated gene activation. ${ }^{21,22}$ GT198 also critically regulates homologous recombination in DNA repair. ${ }^{23-25}$ The genetic location of the human GT198 gene is at chromosome 17q21, $470 \mathrm{~Kb}$ from $B R C A 1$, a locus that has been previously linked to breast and ovarian cancer predisposition. Germline mutations in GT198 have been identified in familial and early-onset breast and ovarian cancer patients. ${ }^{26}$ A germline mutation in GT198 is also found in familial ovarian disease of XX female gonadal dysgenesis. ${ }^{27}$ Somatic mutations in GT198 are prevalent in sporadic fallopian tube and ovarian cancer, which result in altered steroid hormone regulations. ${ }^{28,29}$ GT198 somatic mutations in cancer are clustered in two mutation hotspots that deregulate GT198 alternative splicing, resulting in the production of a truncated protein isoform with constitutive activity in gene activation. ${ }^{28}$ In human ovarian cancer, GT198 is mutated in the hormone-producing luteinized theca cells in the tumor stroma, causing hormone overproduction and GT198 cytoplasmic translocation. ${ }^{29}$ Because GT198 mutations induce tumor-specific cytoplasmic GT198 expression, we reasoned that mutant tumor stroma expressing cytoplasmic GT198 may also reveal precursor lesions in human breast cancer.

\section{Materials and Methods}

\section{Study Design and Human Breast Cancer Samples}

Institutional Review Board approval from each institute was obtained following institutional guidelines using deidentified human breast cancer paraffin sections. Individual patient consent was not required because no human subject was involved. Formalin-fixed, paraffin-embedded (FFPE) sections (5 $\mu \mathrm{m}$ thick) of human breast carcinomas and normal breast controls were derived from the Indiana University School of Medicine (Indianapolis, IN), Medical College of Georgia (Augusta, GA), and Renmin Hospital of Wuhan University (Wuhan, China). In addition, FFPE tumor microarrays ( $5 \mu \mathrm{m}$ thick; 1.5 or $2.0 \mathrm{~mm}$ in diameter) of breast cancers were purchased from Imgenex Corp. (San Diego, CA) and US Biomax Inc. (Rockville, MD). Pathology diagnosis of all samples was verified through histological examination by pathologists (L.C. and L.K.). Breast cancer tissues were screened by immunohistochemistry to identify $\mathrm{GT}_{198^{+}}$reactive tumor stroma with cytoplasmic GT198 expression. Selected eight cases of positive stroma were subjected to DNA sequencing analysis to identify somatic mutations in GT198 using serial cut adjacent sections. As additional negative controls, mutation analysis was performed in genomic DNA isolated from 12 frozen breast tumors derived from Biochain Institute, Inc. (Hayward, CA) and in five breast cancer cell lines (MCF-7, MDA-MB-231, ZR-75-1, MDAMB-436, and MDA-MB-468) originally derived from ATCC (Manassas, VA).

\section{Mutation Analysis}

FFPE sections of breast tumor were deparaffinized through xylene and 100\% ethanol, and air dried. The entire GT198 tumor stroma containing at least $50 \%$ positive cells, identified by immunohistochemistry in an adjacent slide, was removed using a new razor blade and transferred to the tube. For smaller areas of tumor stroma or tumor cells, laser capture microdissection was performed using a Pix-Cell II laser capture microscope and CapSure macro LCM caps, according to the manufacturer's protocol (Arcturus Engineering, Carlsbad, CA). Genomic DNA was isolated by DNeasy Tissue Kit reagents (Qiagen, Valencia, CA). DNA samples were Sanger sequencing analyzed from both directions with repeats in two previously identified mutation hotspot sequences, ${ }^{28}$ at $5^{\prime}$ untranslated region (UTR) to exon 2 (c.-109C to c.103A) and at the exon 4-intron 4 junction (c.265C to c.337+116T). The entire GT198 gene was not analyzed because of the fragmentation of DNA in FFPE sections. Forward (F) and reverse (B) primers are as follows: $5^{\prime}$ UTR-F, 5'-GGGGTCGCTTTGCTCCTCCGGAA-3'; intron 1-B, 5'-CTACGGAGAGAAAGGCAGGGGA-3'; intron 1-F, 5'-CAGTGGGTGAGGAGGTCGGTTGA-3'; exon 2-B, 5'-AGTCCGTGTTCCCGCTGTAGGT-3'; exon 4-F, 5'-GTGAGTGATGCTGACCTTCAAGTC- $3^{\prime}$; and intron 4-B, 5'-TACACAAAAGCCGTTAGTTATCCT- $3^{\prime}$. Nucleotide numbering was based on the cDNA reference sequence. To confirm sequencing signals, amplified PCR products containing mutant alleles were cloned into pGEM-T Easy TA cloning vector (Promega, Madison, WI). Multiple clones were sequenced to detect mutant alleles. For genomic DNA derived from frozen breast tumors and cancer cell lines, Sanger sequencing was performed in the entire GT198 gene (c. $131 \mathrm{G}$ to c. $* 316 \mathrm{C}$ ), excluding the large intron 3 (c.225+160A to c.226-96G).

\section{Immunohistochemistry}

Polyclonal antiserum against GT198 was previously prepared in rabbits (Covance, Denver, PA). ${ }^{21}$ Affi-gel 10 affinity resins were covalently cross-linked to his-tagged GT198 protein as antigen for affinity purification of anti-GT198, according to the manufacturer's protocol (Bio-Rad, Hercules, CA). FFPE breast tumor sections or tumor microarrays were deparaffinized and dehydrated through xylene and ethanol series, followed by antigen retrieval in $10 \mathrm{mmol} / \mathrm{L}$ sodium citrate buffer, $\mathrm{pH}$ 6.0, containing $0.05 \%$ Triton at $90^{\circ} \mathrm{C}$ for $20 \mathrm{mi}-$ nutes. Anti-GT198 (1:200) was incubated at $4^{\circ} \mathrm{C}$ overnight. Antibody binding was detected using biotinylated anti-rabbit secondary antibody, followed by detecting reagents (Abcam, Cambridge, MA). Sections were counterstained with hematoxylin. Immunohistochemistry staining was scored in identified $\mathrm{GT}_{198^{+}}$breast tumor stroma in four categories of cells, including myoepithelial cells, adipocytes, perivascular cells or pericytes, and fibroblasts. The presence of positive cells was scored by the percentage in each category in $10 \%$ increments. Scored data were graphed by scattergram using 
GraphPad (La Jolla, CA) Prism 3.0 software with analyzed case numbers $(n)$ indicated.

\section{Immunofluorescence}

GT198 expression was first identified by immunohistochemistry in tumor stroma, and the adjacent sections were further analyzed by immunofluorescence double staining. Paraffinembedded tissue sections were deparaffinized through xylene and ethanol series, followed by antigen retrieval, as above. Immunofluorescence double staining was performed in $1 \%$ horse serum using rabbit anti-GT198 (1:200) and mouse antiCD44 (1:200, Ab-4, clone 156-3C11; Lab Vision Corp., Fremont, CA), mouse anti-vascular endothelial growth factor (VEGF; 1:200, sc-7269; Santa Cruz Biotechnology, Dallas, TX), or mouse anti- $\alpha$-smooth muscle actin (1:200, A2547; Sigma, St. Louis, MO). Secondary antibodies were anti-mouse Alexa Fluor 488- and anti-rabbit Alexa Fluor 594-conjugated antibodies (Invitrogen, Carlsbad, CA). Sections were counterstained with DAPI.

\section{GFP Transfection and Oil Red 0 Staining in Mouse Mammary Gland Primary Culture}

Mouse mammary gland tissues from wild-type FVB mouse were digested in $0.5 \mathrm{mg} / \mathrm{mL}$ collagenase IV in phosphatebuffered saline at $37^{\circ} \mathrm{C}$ for 3 hours. Cells were cultured in Dulbecco's modified Eagle's medium supplemented with $10 \%$ fetal bovine serum, $2 \mathrm{mmol} / \mathrm{L}$ glutamine, $100 \mathrm{U} / \mathrm{mL}$ penicillin, and $0.1 \mu \mathrm{g} / \mu \mathrm{L}$ streptomycin, and incubated in $5 \% \mathrm{CO}_{2}$ at $37^{\circ} \mathrm{C}$. Attached surviving cells were transfected overnight in chamber slides with green fluorescent protein (GFP)-GT198 (wild type, 1 to 217 amino acids) and GFP-mutant GT198 (126 to 217 amino acids) plasmids in pEGFP-C3 vector. For fluorescent staining, transfected cells were methanol fixed, stained by antiVEGF and Alexa Fluor 594, and imaged for GFP in green and VEGF in red. For oil red $\mathrm{O}$ staining, transfected cells were fixed with $10 \%$ formalin, stained by oil red $\mathrm{O}$, and imaged for GFP in green and oil red $\mathrm{O}$ in red. Oil red $\mathrm{O}$ staining can be detected by red fluorescence. Oil red $\mathrm{O}-$ stained transfected cells were also hematoxylin counterstained and imaged by bright field microscopy. Quantification of oil red O staining was performed by transfection of GT198 or its mutant plasmids in a 24-well plate for 8 days $(n=6)$. Cells were oil red $\mathrm{O}$ stained and dissolved in $200 \mu \mathrm{L}$ of $100 \%$ isopropanol, which was transferred to a 96-well clear plate and read at $\mathrm{A}_{500}$.

\section{GFP Transfection and RT-PCR in MEF}

Mouse embryonic fibroblast (MEF) cells were prepared using C57BL/6 mouse embryos at embryonic day 14.5. Briefly, head and internal organs were removed from the embryos which were rinsed in phosphate-buffered saline after digestion in $0.05 \%$ trypsin/EDTA by pipetting. Cells were collected by centrifugation after inactivation of trypsin by adding fresh above Dulbecco's modified Eagle's medium. For fluorescent staining, GFP fusions of GT198 or mutant were transfected into MEF cells in chamber slides and stained using the same protocol described above for markers of angiogenesis and adipogenesis. Marker antibodies used are as follows: von Willebrand factor (A0082; Dako, Carpinteria, CA); peroxisome proliferator-activated receptor $\gamma(2430)$ and CCAAT-enhancerbinding protein $\alpha$ (2295) (both from Cell Signaling Technology, Danvers, MA); and VEGF (sc-7269), sterol regulatory element-binding protein 1 (sc-366), and fatty acid synthase (sc-715) (all from Santa Cruz Biotechnology, Dallas, TX). For enzyme-linked immunosorbent assay (ELISA), freshly prepared MEF cells were transfected overnight in a 6-well plate with 0.5 or $2 \mu \mathrm{g}$ of wild-type GT198 or mutant GT198 plasmids. Cell culture medium was collected for ELISA to measure secreted VEGF protein. Briefly, a white 96-well plate was first coated with $50 \mathrm{ng}$ per well rabbit anti-VEGF as capture antibody (RB-9031; Thermo Scientific, Waltham, MA), together with $5 \mu \mathrm{g}$ per well bovine serum albumin. The washed plate was incubated with culture medium of transfected cells $(250 \mu \mathrm{L}$ per well) for 16 hours at $4^{\circ} \mathrm{C}$. VEGF binding was detected by mouse anti-VEGF (1:1000, sc-7269) and horseradish peroxidase-conjugated anti-mouse antibody (1:3000, 074-1807; KPL, Gaithersburg, MD), following detection reagents. For RT-PCR, RNA from the same 6-well transfected MEF cells was isolated by Trizol and analyzed using a one-step RT-PCR kit (Qiagen, Valencia, CA). Mouse VEGF primers are as follows: forward, F-exon1, 5'-GGCCTCCGAAACCATGAACTT-3'; reverse, B-exon3, 5'-GGGTACTCCTGGAAGATGTC- $3^{\prime}$.

\section{VEGF Promoter Luciferase Assay}

Human VEGF promoter fragments ( -1228 to $19,-1228$ to 420 , and -1970 to 19 ) were PCR amplified using normal human genomic DNA as template $(100 \mathrm{ng} / 100 \mu \mathrm{L}$; Clontech, Mountain View, CA). The PCRs were optimized by adding the Qiagen Q solution to resolve high GC-rich secondary structures in the VEGF promoter. ${ }^{30}$ Cloning primers with restriction enzyme sites underlined were as follows: forward primers: F1970, 5'-GATTCCAAGCTTATCCCGTTCATCAGCCTAGAGCAT-3'; F1228, 5'-GATTCCAAGCTTATGAGTCTGGGCTTGGGCTGATAG-3'; reverse primers: B19, 5'-TTACACCTCGAGCTGCCCCAAGCCTCCGCGATCCT-3'; and B420, 5'-CGACACCTCGAGCACTTTGCCCCTGTCGCTTTCGCT- $3^{\prime}$. VEGF promoter fragments were inserted into a promoter-less luciferase reporter pXP2 (HindIII-XhoI), confirmed by restriction mapping and partial DNA sequencing. For luciferase assays, CV-1 cells were maintained in above Dulbecco's modified Eagle's medium in $5 \% \mathrm{CO}_{2}$ at $37^{\circ} \mathrm{C}$. Cells were transfected in triplicate in 24-well plates using Lipofectin (Invitrogen, Carlsbad, CA) together with $0.1 \mu \mathrm{g}$ per well VEGFluciferase reporter plasmid and other plasmids at indicated concentrations. Human GT198 (1-217), its mutant (126-217), estrogen receptor $\alpha(\mathrm{ER} \alpha)$, and PR were in cytomegalovirusdriven pcDNA3 vector. Mitogen-activated protein (MAP) kinase plasmid pFC-MEKK expressed an activated catalytic 
A
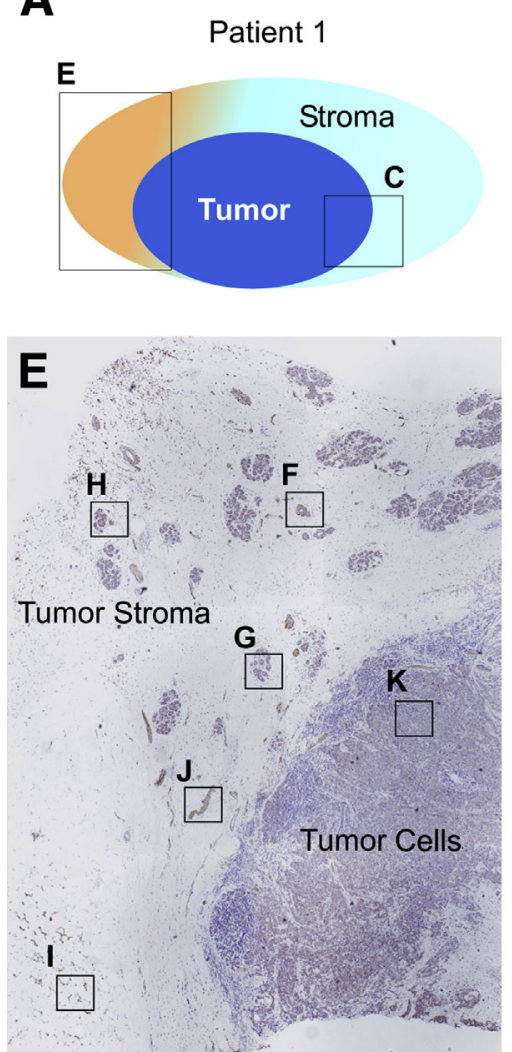
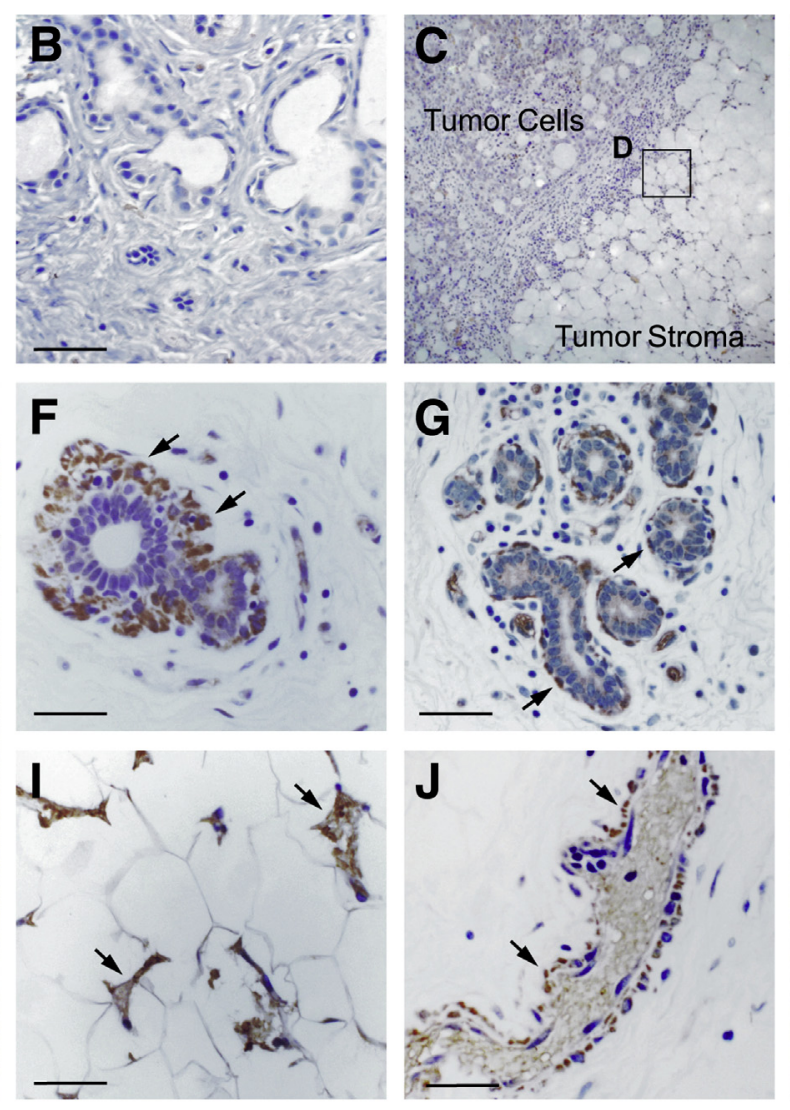
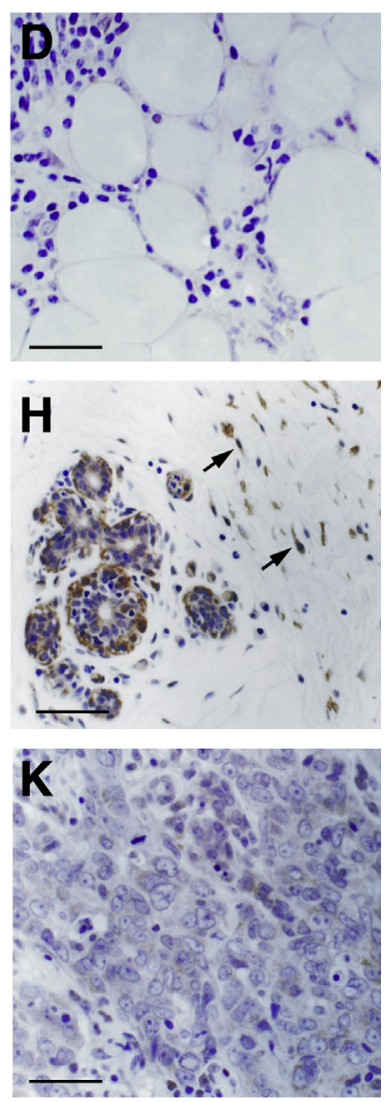

Figure 1 Cytoplasmic GT198 expression in human breast tumor stromal cells. Immunohistochemical staining of GT198 in ductal carcinoma of Patient 1. A: A model shows positive stroma in orange and negative stroma in blue surrounding the tumor on the section. B: Normal human breast tissue as a control. $\mathbf{C}$ and D: Negative stroma (C) with boxed area enlarged (D). E: Positive stroma contains carcinoma in situ (grouped images). Boxed areas are enlarged in F-K. F: GT198 ${ }^{+}$myoepithelial cells in acinus. G: Reduced myoepithelial layer in carcinoma in situ. H: GT198 ${ }^{+}$stromal fibroblasts. I: GT198 ${ }^{+}$adipocytes in fat pad. J: $\mathrm{GT}_{198}{ }^{+}$capillary pericytes encircling endothelium. K: GT198 ${ }^{-}$epithelial tumor cells. Arrows indicate GT198 ${ }^{+}$cells with cytoplasmic GT198 (F-J). Sections are counterstained with hematoxylin. Original magnification, $\times 50$ (C and $\mathbf{E})$. Scale bar $=50 \mu \mathrm{m}(\mathbf{B}, \mathbf{D}$, and $\mathbf{F}-\mathbf{K})$.

domain of RAF kinase that activates MAP kinase cascade. Hormone ligands were $17 \beta$-estradiol for $\mathrm{ER} \alpha$ and progesterone for PR (100 nmol/L). Cells were harvested 16 hours after transfection, and relative luciferase activities were measured by a Dynex luminometer (Dynex Technologies, Inc., Chantilly, VA). Data are presented as means \pm SEM of triplicate transfections.

\section{Statistical Analysis}

Statistical analyses were performed using GraphPad Prism software. Scattergrams with means are presented in immunohistochemical staining and quantification of oil red $\mathrm{O}$ staining. Bar graphs are presented in ELISA and luciferase assays. $P$ values were calculated using an unpaired two-tailed $t$-test. $P<0.05$ was considered statistically significant.

\section{Results}

GT198 Expression in Myoepithelial Cells, Adipocytes, Pericytes, and Fibroblasts of Human Breast Cancer Stroma

We have previously found cytoplasmic GT198 expression in mutant ovarian cancer stromal cells. ${ }^{29}$ To identify precursor lesions in human breast cancer, we analyzed GT198 cytoplasmic expression in a total of 249 cases of human breast cancer and 11 cases of normal breast controls by immunohistochemistry (Figures 1, A-E, and 2A). Although GT198 was absent in normal breast tissue (Figure 1B), or nonreactive tumor stroma (Figure 1, C and D), it was strongly expressed in focal reactive tumor stroma (Figure 1E). Reactive breast tumor stroma is generally defined by morphological and molecular criteria as early lesions containing carcinoma in situ, with increased tumor-associated fibroblasts, inflammation, and apoptosis. ${ }^{31,32}$ GT198 $^{+}$cells included myoepithelial cells that were gradually lost in developing carcinoma in situ (Figure 1, F and G). GT198 ${ }^{+}$cells also included stromal fibroblasts (Figure $1 \mathrm{H}$ ), and adipocytes in the fat pad (Figure 1I). Significant angiogenesis was present in $\mathrm{GT} 198^{+}$stroma, where capillary pericytes expressed GT198 (Figure 1J). In contrast to stromal cells, tumor cells derived from the epithelial layer were largely absent of GT198 expression (Figure 1K).

The above data indicate that GT198 is expressed in stromal myoepithelial cells, adipocytes, perivascular cells or pericytes, and fibroblasts in reactive breast tumor stroma. Negative stroma is often juxtaposed to the tumor so that 

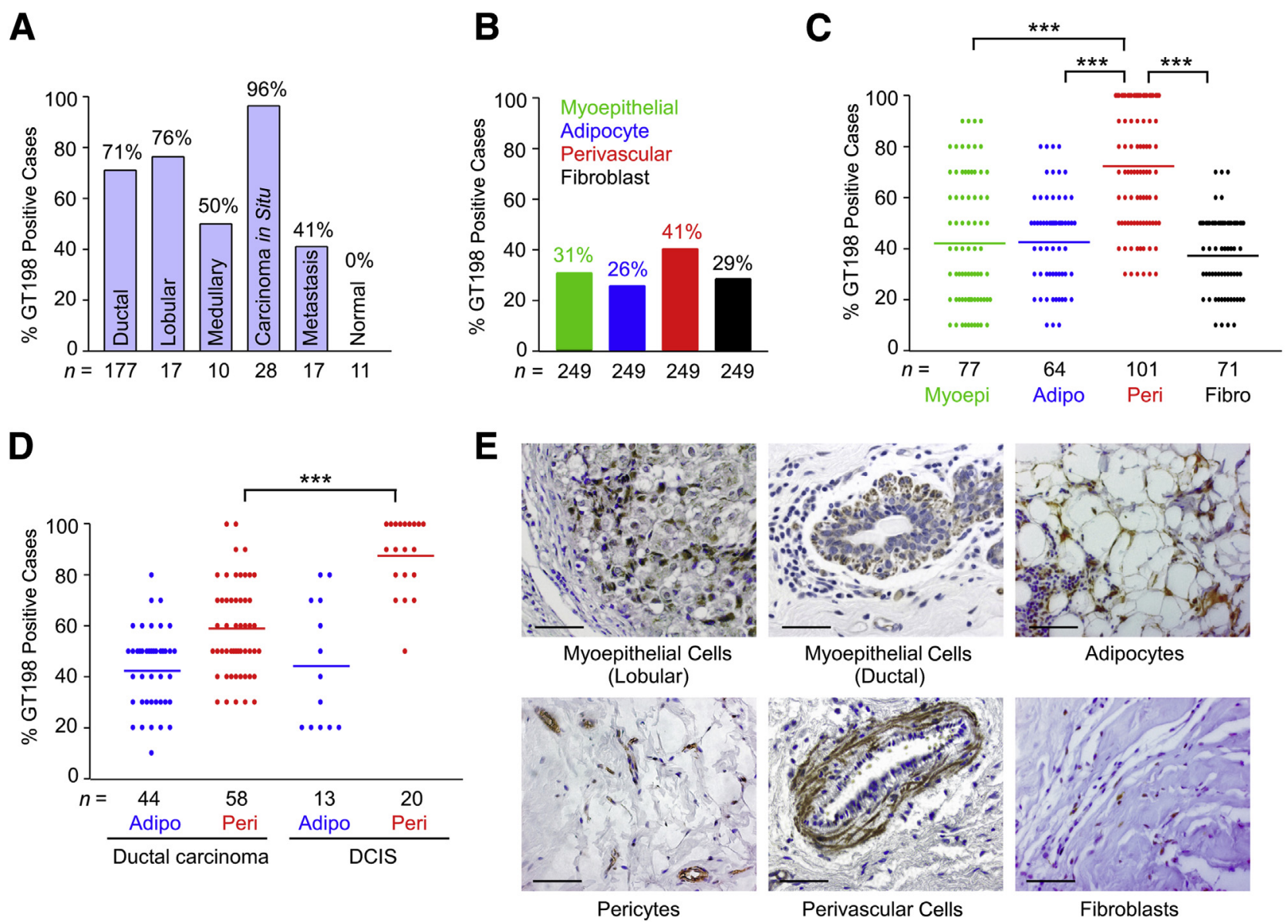

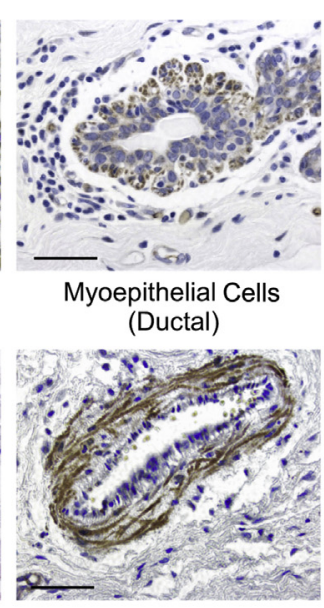

Perivascular Cells
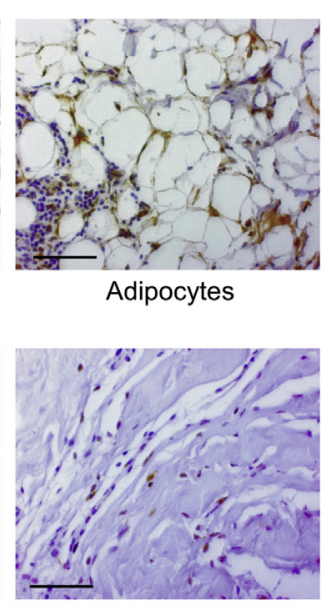

Fibroblasts

Figure $2 \mathrm{GT}_{198}{ }^{+}$perivascular (Peri) cells are abundant in carcinoma in situ. Immunohistochemical staining of GT198 in 249 cases of breast cancers and 11 cases of normal breast tissues. Number of cases $(n)$ analyzed are indicated. A: Percentage of GT198 ${ }^{+}$cases in each type of breast cancer. B: Percentage of GT198 ${ }^{+}$cases in each category of stromal cells. C: Percentage of $\mathrm{GT}_{198}{ }^{+}$cells in $10 \%$ increments in each category of stromal cells. D: Comparison of GT198 ${ }^{+}$adipocytes (Adipo) and perivascular cells between ductal carcinoma and ductal carcinoma in situ (DCIS). E: Representative immunohistochemical staining of GT198 in each category of breast tumor stromal cells. Sections are counterstained with hematoxylin. ${ }^{* *} P<0.0001$. Scale bar $=50 \mu \mathrm{m}(\mathbf{E})$. Fibro, fibroblast; Myoepi, myoepithelial.

both reactive stroma and normal stroma are concurrently present (Figure 1). Thus, GT198 expression is a specific marker of reactive tumor stroma, which often contains carcinoma in situ and increased angiogenesis.

\section{$\mathrm{GT}_{198}{ }^{+}$Perivascular Cells Are Abundant in Carcinoma in Situ}

In 249 cases of breast cancer analyzed, cytoplasmic GT198 was present in tumor stroma of both ductal and lobular carcinomas (Figure 2A). Carcinoma in situ showed the highest positive rate (96\%), suggesting that GT198 is associated with early lesions (Figure 2A). Negative cases were more often observed in advanced tumors lacking stromal cell populations. Hence, the true-positive rates may potentially be even higher than reported herein. When each of the four categories of positive cells was analyzed, the GT198 ${ }^{+}$perivascular cell type was the most significant (Figure 2B). In fact, GT198 ${ }^{+}$capillaries were the most common feature identified in GT198 ${ }^{+}$tumor stroma. We scored immunohistochemistry staining by percentage of positive cells in each cell type (Figure 2, C and D), with their representative images shown in Figure 2E. When analyzed by immunohistochemical scores, GT198 ${ }^{+}$perivascular cells also displayed a significantly higher percentage than myoepithelial cells, adipocytes, or fibroblasts (Figure 2C). In many cases, all perivascular cells were positive in a given sample. When carcinoma in situ was compared with carcinoma, $\mathrm{GT}_{198^{+}}$perivascular cells were significantly more abundant (Figure 2D), whereas GT $198^{+}$adipocytes were not significantly different. These data suggest that $\mathrm{GT}_{198}{ }^{+}$perivascular cells are associated with early-stage breast cancer.

\section{GT198 $^{+}$Breast Cancer Stroma Harbors GT198 Somatic Mutations}

Cytoplasmic GT198 expression is previously found to be a consequence of GT198 genetic mutations. ${ }^{26,28,29} \mathrm{We}$, therefore, performed sequence analysis of positive breast tumor stroma to identify GT198 mutations. We selected eight positive cases and performed Sanger sequencing spanning previously identified GT198 mutation hotspots (Figure $3 \mathrm{~A}){ }^{28}$ Mutations were identified in 7 (87.5\%) of 8 


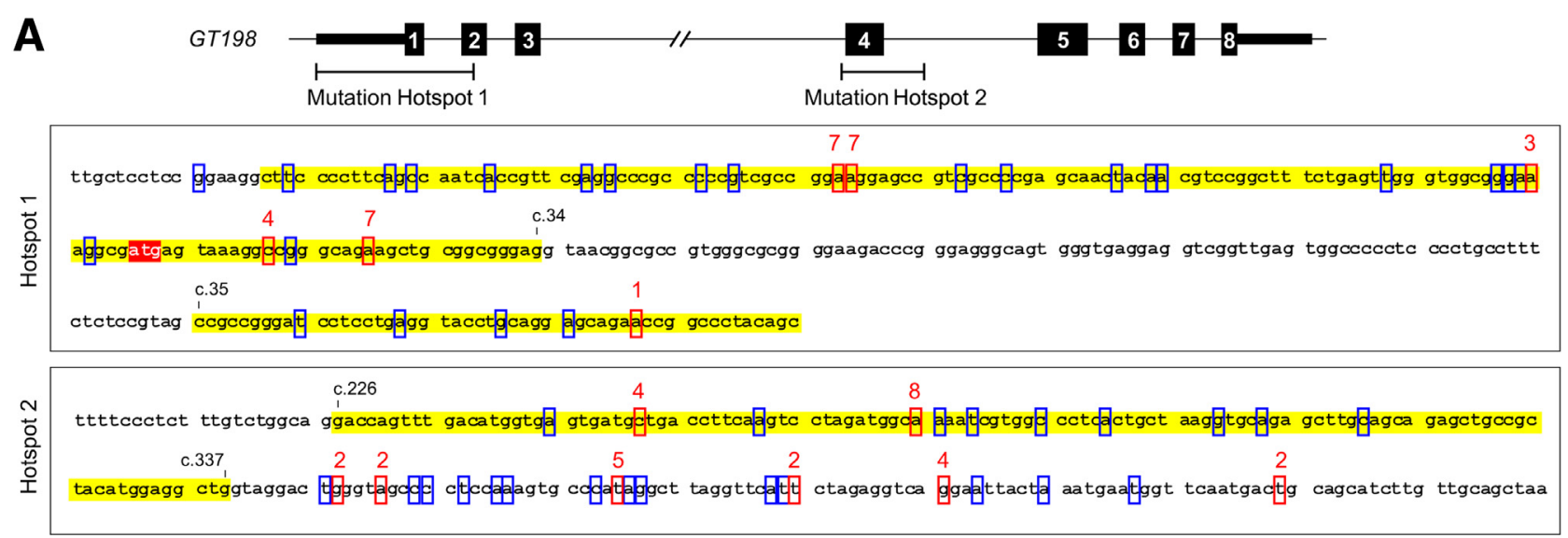

B

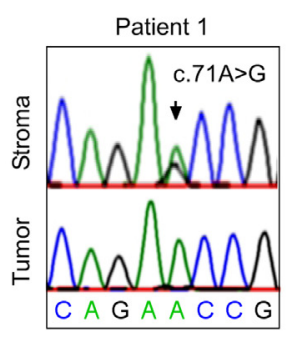

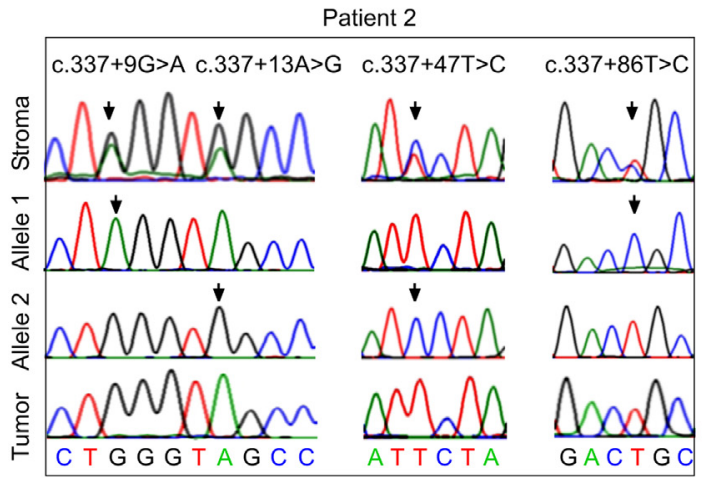

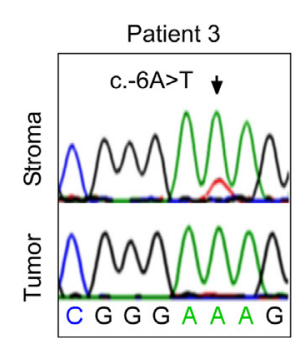

Figure $3 \mathrm{GT}_{198}{ }^{+}$breast cancer stroma harbors GT198 somatic mutations. A: A diagram of the human GT198 gene is depicted with numbered boxes as exons and lines as introns. Nucleotide sequences of the two mutation hotspots are shown with exons in yellow and start codon in red. Previously identified germline and somatic mutations in GT198 in cancer are labeled in blue. ${ }^{26,28,29}$ Mutations identified in breast cancer from this study are labeled in red with patient number indicated above (Table 1). Mutation numbering is on the basis of the cDNA reference sequence. B: Representative sequence trace chromatograms from tumor stroma and tumor of Patients 1 to 3 . Cloned stromal alleles are shown for comparison. Tumor has wild-type GT198 sequences. Arrows indicate nucleotide changes.

cases (Table 1). In Patient 1 (Figure 1), a GT198 somatic mutation $(\mathrm{c} .71 \mathrm{~A}>\mathrm{G})$ was identified in stroma but not in microdissected tumor cells, suggesting the mutation was somatic (Figure 3B). In a triple-negative ductal carcinoma from Patient 2 (Supplemental Figure S1), a total of four somatic mutations were identified in stromal cells but not in tumor cells (Figure 3B and Table 1). Cloning and analysis of mutant alleles showed that two alleles were mutated, although each allele could be derived from a subpopulation of mutant cells. As controls, we did not detect any GT198 mutations in 12 frozen breast epithelial tumors or in five breast cancer cell lines, including MCF-7, MDA-MB-231, ZR-75-1, MDA-MB-436, and MDA-MB468 , suggesting that epithelial tumor cells or their derivatives lack GT198 mutations. GT198 ${ }^{-}$epithelial tumor cells likely have a distinct origin from $\mathrm{GT}_{198^{+}}$stromal cells. Because Sanger sequencing requires a mutant cell population carrying the same mutation to be detectable, our observations also imply that multiple lineages of mutant stromal cells are related and are possibly differentiated from mutant common precursors carrying the initial mutation. Our results indicate that $\mathrm{GT} 198^{+}$breast tumor stromal cells carry GT198 somatic mutations.

\section{$\mathrm{GT}_{198}{ }^{+}$Pericytes Contain Progenitors Expressing VEGF}

To better understand the functional consequence of GT198 mutations, we further analyzed the mutant tumor stroma from Patient 2 (Supplemental Figure S1). A breast

Table 1 GT198 Mutations in Breast Tumor Stroma

\begin{tabular}{llll}
\hline Patient no. & Age, years & Pathology diagnosis & Location \\
\hline 1 & 72 & Ductal & Exon 2 \\
2 & 70 & Ductal (TNBC) & Intron 4 \\
3 & 58 & Ductal & Exon 1 \\
4 & 53 & Lobular & Exons 1 and 4 \\
& & & and intron 4 \\
5 & 60 & Ductal & Intron 4 \\
6 & 78 & Ductal & - \\
7 & 42 & Lobular & Exon 1 \\
8 & 50 & Ductal & Exon 4 \\
\hline
\end{tabular}

Detected allelic mutations with amino acid changes in parentheses: Patient 1, c.71A $>$ G (N24S). Patient 2, c.337+9G $>A$; c.337+13A $>$ G; c. $337+47 \mathrm{~T}>\mathrm{C} ;$ c. $337+86 \mathrm{~T}>$ C. Patient 3, c. $-6 \mathrm{~A}>\mathrm{T}$. Patient 4, c. $12 \mathrm{C}>\mathrm{T}$; c. 251C $>$ G (A84G); c.337+58G $>$ A. Patient 5, c.337+32T $>$ C. Patient 7, c. $-62 A>T$; c. $-63 A>T$; c.20A $>$ T (E7V). Patient 8, c.274A $>$ G (K92E).

-, mutation undetectable in Patient 6; TNBC, triple-negative breast cancer. 
progenitor marker, CD44, was double stained with GT198, and $\mathrm{GT}_{198^{+}}$pericytes in capillaries were found to be mostly $\mathrm{CD} 44^{+}$, whereas adipocytes and myoepithelial cells had a few $\mathrm{CD}_{4} 4^{+}$cells (Figure 4A). In contrast, GT198 ${ }^{+}$ perivascular cells in a large blood vessel had no CD44 ${ }^{+}$ cells, suggesting that capillaries possess most of the $\mathrm{GT}_{198}{ }^{+}$progenitors. Because VEGF induces angiogenesis with increased capillaries, ${ }^{33,34}$ we analyzed VEGF expression and found that VEGF was highly expressed in GT198 ${ }^{+}$ pericytes, perivascular cells, and some adipocytes (Figure 4A). By comparison, VEGF expression was absent in most myoepithelial cells (Figure 4A). As controls, $\alpha$ smooth muscle actin, a marker for vascular smooth muscle cell lineage, was expressed in all four cell types of interest (Figure 4A). These results indicate that $\mathrm{GT}_{198^{+}}$progenitor cells are mostly pericytes that express VEGF.

\section{Mutant GT198 Induces VEGF Expression and Promotes Adipogenesis}

Mutations in GT198 have been previously observed in fallopian tube and ovarian cancers that disrupt GT198 alternative splicing. ${ }^{26,28,29}$ Various splicing mutations led to the production of an activated C-terminal half mutant protein that can translocate into cytoplasm. ${ }^{29}$ The GT198 mutations identified in the present study are similarly located in sequences that potentially disrupt alternative splicing (Figure 3A), and result in the same mutant GT198 protein. We then tested whether mutant GT198 protein induces VEGF expression using cell culture models. In mouse mammary gland-derived primary culture, GFP fusion GT198 and its mutant were transiently transfected, and endogenous VEGF expression was analyzed by immunofluorescence. The results showed that the mutant, but not wild-type, GT198 induced a high level of VEGF expression (Figure 4B). Although the wild-type GT198 is expressed in the nucleus, the mutant is known to cause condensed nuclei with its expression in both nucleus and cytoplasm. ${ }^{28}$ In transfected cells expressing mutant GT198, data clearly showed that nuclei were small, GFP expression was spread into cytoplasm, VEGF was induced, and adipogenesis was present, with the lipid droplets stained by oil red O (Figure 4B and Supplemental Figure S2). Bright field images also showed lipid droplets in mutanttransfected cells (Figure 4B and Supplemental Figure S2). When oil red $\mathrm{O}$ staining was quantified using isopropanol extraction of stained transfected cells, a significant increase in
A
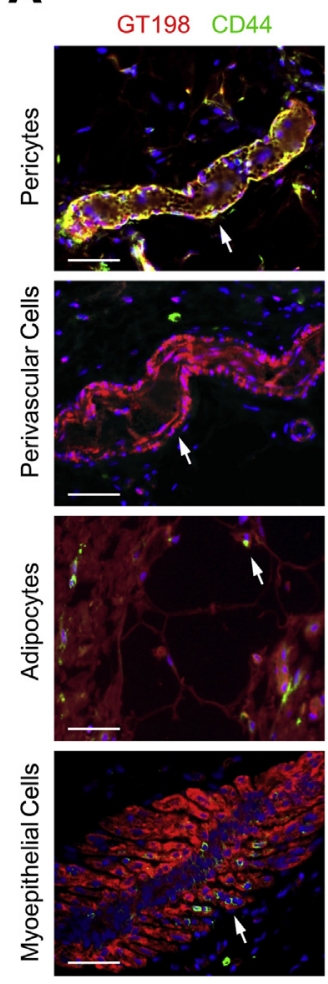

Patient 2

GT198 VEGF
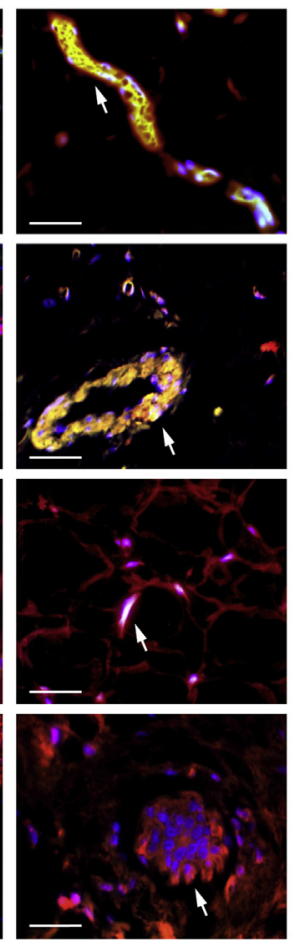

GT198 $\alpha$ SMA
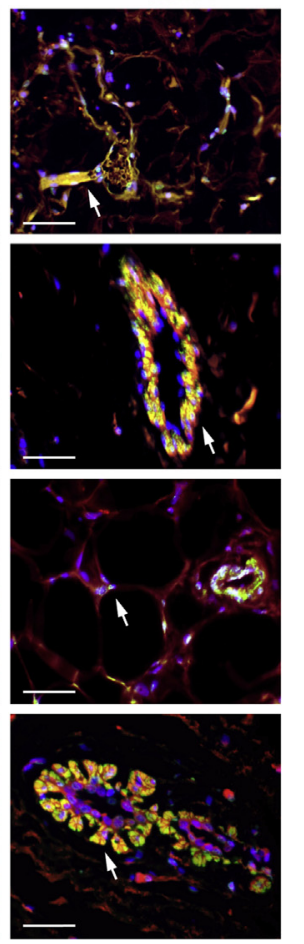

B

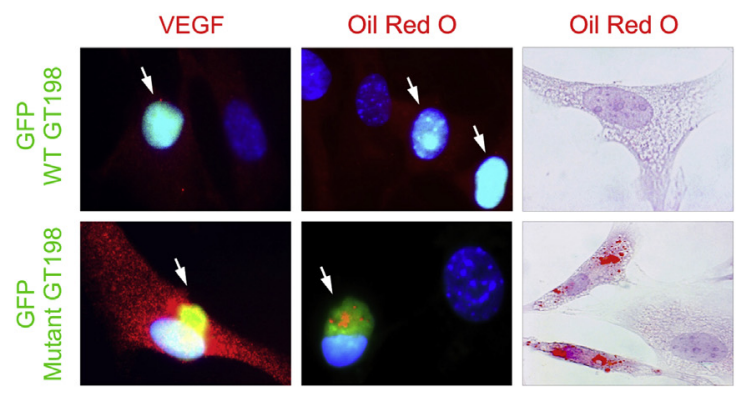

C

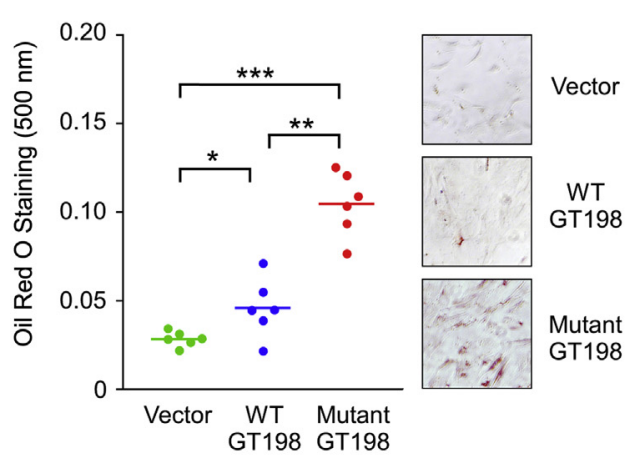

Figure 4 Mutant GT198 induces vascular endothelial growth factor (VEGF) expression and promotes adipogenesis. A: Immunofluorescence double staining of GT198 in red and CD44, vascular endothelial growth factor (VEGF), and $\alpha$-smooth muscle actin ( $\alpha$-SMA) in green in pericytes, perivascular cells, adipocytes, and myoepithelial cells of tumor stroma derived from Patient 2 (Supplemental Figure S1). Arrows indicate cells of interest. Sections are counterstained with DAPI in blue. B: Green fluorescent protein (GFP) fusion plasmids expressing wild-type (WT) GT198 (1 to 217) in nucleus and mutant GT198 (126 to 217 ) in cytoplasm were transfected in primary cultured cells of mouse mammary glands. Transfected cells were stained using anti-VEGF (left) or oil red 0 (middle), and fluorescent imaged with GT198 fusion proteins in green, VEGF in red, oil red 0 in red, and DAPI in blue. Arrows indicate transfected cells. Hematoxylin was counterstained in the bright field images (right). Supplemental Figure S2 provides additional data. C: 0il red 0 staining was quantified in transfected cells. An unpaired two-tailed $t$-test was used. ${ }^{*} P<0.01,{ }^{* *} P<0.001$, and ${ }^{* * *} P<0.0001 . n=6$ (C). Scale bar $=50 \mu \mathrm{m}(\mathbf{A})$. 

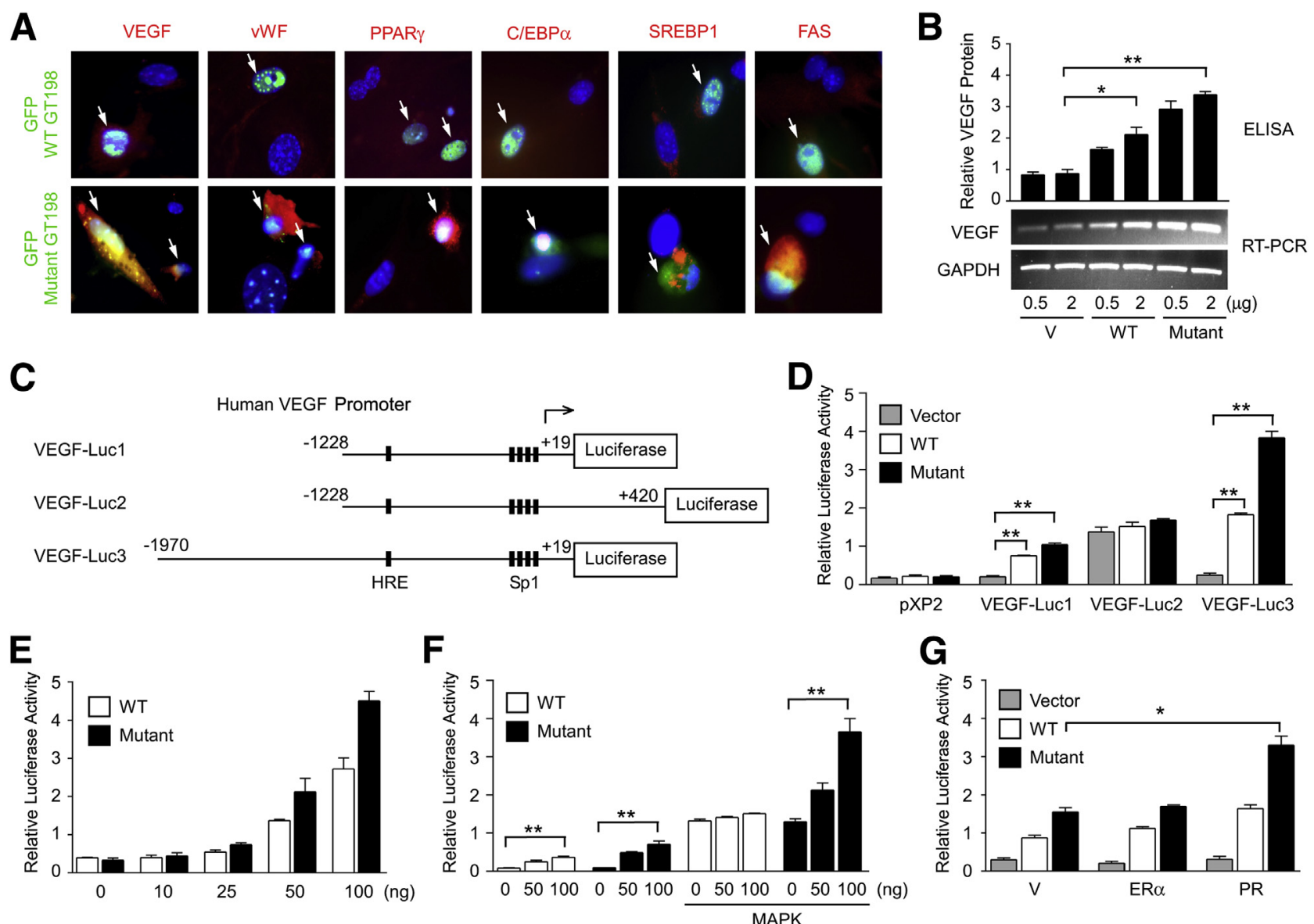

Figure 5 Mutant GT198 stimulates human vascular endothelial growth factor (VEGF) promoter. A: Immunofluorescence staining of green fluorescent protein (GFP)-GT198 and GFP-mutant GT198 in transfected mouse embryonic fibroblast (MEF) cells. GFP fusions are stained in green; VEGF, von Willebrand factor (VWF), peroxisome proliferator-activated receptor $\gamma$ (PPAR $\gamma$ ), CCAAT-enhancer-binding protein $\alpha$ (C/EBP $\alpha$ ), sterol regulatory element-binding protein 1 (SREBP1), and fatty acid synthase (FAS) are detected by antibodies and stained in red; and DAPI is stained in blue. Arrows indicate transfected cells. B: MEF cells were transfected in a 6-well plate with indicated amounts of plasmids expressing wild-type (WT) and mutant GT198. Secreted VEGF protein in culture medium was measured by enzyme-linked immunosorbent assay (ELISA), and VEGF mRNA was measured by RT-PCR using glyceraldehyde-3-phosphate dehydrogenase (GAPDH) as a control. C: Schematic diagrams of human VEGF promoter luciferase reporters with hypoxia-response element (HRE) and Sp1-binding sites labeled as bars. Numbers indicate nucleotides from transcriptional start site. D: CV-1 cells were cotransfected in a 24-well plate with GT198 or its mutant (100 ng) and VEGF-Luc1 to 3 (100 ng) as indicated. E: VEGF-Luc3 was cotransfected in CV-1 cells with a different dose of GT198 or mutant as indicated. F: Mitogen-activated protein kinase (20 ng) effect was tested using VEGF-Luc3 with different dose of GT198 or mutant ( 0 to $100 \mathrm{ng}$ ). G: Estrogen receptor $\alpha($ ER $\alpha$ ) or progesterone receptor (PR; 20 $\mathrm{ng}$ ) was tested using VEGF-Luc3 under the treatment of hormone ligands $17 \beta$-estradiol or progesterone (100 nmol/L), respectively. Relative luciferase light units were shown. An unpaired two-tailed $t$-test was used. Data are given as means \pm SEM of triplicate transfections (D-G). $n=3$ $(\mathbf{D}-\mathbf{G}) .{ }^{*} P<0.01,{ }^{*} P<<0.001$. V, vector control.

staining was observed in cells expressing mutant GT198 than vector control or wild-type GT198 (Figure 4C). These results suggest that mutant GT198 protein induces VEGF expression and also promotes adipogenesis.

To further confirm that mutant GT198 induces angiogenesis and adipogenesis, we analyzed additional markers in mouse embryonic fibroblast (MEF) cells, which have multipotent differentiation capacity. The data showed that mutant GT198 induced expression of angiogenic markers VEGF, von Willebrand factor, and adipogenic markers peroxisome proliferator-activated receptor $\gamma$, CCAATenhancer-binding protein $\alpha$, sterol regulatory elementbinding protein 1 , and fatty acid synthase in MEF cells
(Figure 5A). Although wild-type GT198 also induced weak VEGF expression, mutant GT198 potently induced all markers tested. Because mutant GT198 is essentially a C-terminal half of the wild-type protein, our results imply that wild-type GT198 activity is likely regulated under physiological conditions and cancer-specific mutant protein is a constitutively activated form. To quantify VEGF expression, MEF cells were transfected using different concentrations of wild-type or mutant GT198 plasmids. Secreted VEGF protein in medium was measured by ELISA, and VEGF mRNA expression by RT-PCR. Data suggested that mutant GT198 was more potent than the wild-type in stimulating VEGF protein and mRNA expression in MEF cells 


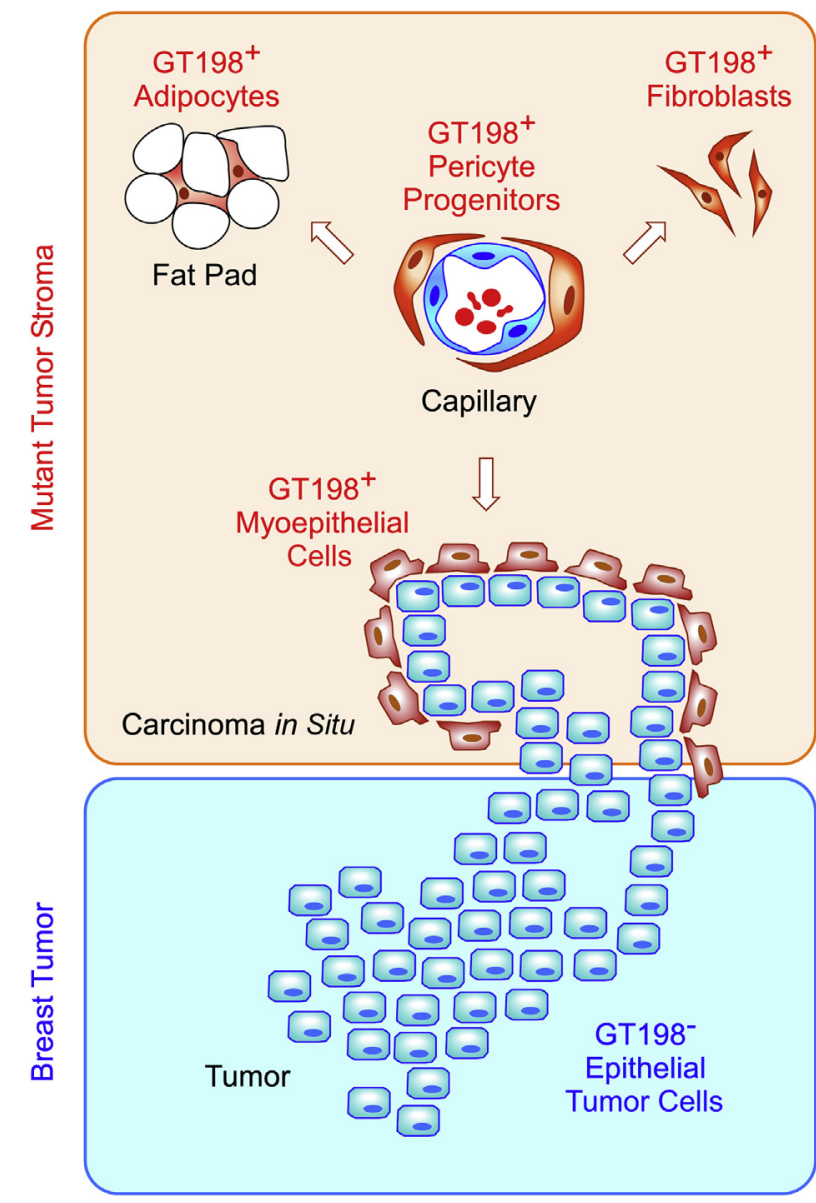

Figure 6 Hypothetical model of mutant GT198 in breast cancer stroma. $\mathrm{GT}_{198}{ }^{+}$tumor stromal sells are depicted in red. Endothelial and luminal epithelial tumor cells are depicted in blue. Potentially, $\mathrm{GT}_{198}{ }^{+}$pericytes in capillaries carry GT198 mutations. The mutant $\mathrm{GT}_{198}{ }^{+}$pericytes differentiate into adipocytes in fat pad, fibroblasts in stroma, and myoepithelial cells lining luminal epithelium. The $\mathrm{GT}_{198}{ }^{+}$cell populations yield a mutant reactive tumor stoma overexpressing cytoplasmic GT198 protein shown in the top panel in orange. The stimulated luminal epithelial cells, absence of GT198 mutation, outgrow the stromal cells to produce breast tumor mass shown in the bottom panel in blue.

(Figure 5B). Together, our results indicate that mutant GT198 is capable of stimulating the expression of multiple angiogenic and adipogenic markers.

\section{Mutant GT198 Stimulates Human VEGF Promoter}

Because mutant GT198 protein induced potent expression of VEGF, we tested whether it stimulates VEGF promoter transcriptional activity. Human VEGF promoter-luciferase reporter constructs were prepared by cloning of VEGF promoter fragments into a promoter-less luciferase vector pXP2 (Figure 5C and Supplemental Figure S3). The human VEGF transcripts exhibit extensive alternative splicing with a long $5^{\prime}$ UTR and multiple translation start sites. ${ }^{35} \mathrm{We}$ tested cloned VEGF promoter fragments spanning -1970 to 19 and -1228 to 19 , and also included 5'UTR spanning -1228 to 420 for its potential activity. The results showed that mutant GT198 was more potent than the wild-type in stimulating VEGF promoter, and the longer promoter was more inducible by mutant GT198 (Figure 5D). Inclusion of $5^{\prime}$ UTR increased basal activity but diminished inductivity (Figure 5D), implicating that $5^{\prime}$ UTR may participate in promoter activation but not pertain to GT198 activation. The induction by GT198 or its mutant was also dose dependent when tested in the longer promoter (Figure 5E). We have previously shown that MAP kinase can suppress wild-type GT198 transcriptional activity. ${ }^{21}$ Herein, although MAP kinase increased basal activity of VEGF promoter, MAP kinase diminished GT198 induction, but not its mutant induction (Figure 5F). These data further supported that mutant GT198 escaped signaling regulations and was constitutively active. When ER $\alpha$ and PR were tested by cotransfections, PR, but not ER $\alpha$, moderately enhanced VEGF promoter activity (Figure 5G), which was consistent with a previous report. ${ }^{36}$ Because the human VEGF promoter is known to be regulated by a large number of cellspecific factors, our results together indicate that GT198 is one of the players in regulating human VEGF promoter, so that active mutant GT198 may promote tumor angiogenesis through stimulating VEGF promoter.

\section{Discussion}

Mounting evidence has shown that breast cancer stromal cells may play an important role in cancer initiation. ${ }^{2,15,17}$ The most critical tumor stromal cell types implicated to date include myoepithelial cells, adipocytes, pericytes, and stromal fibroblasts. Finding the relationships among stromal cell populations in highly heterogeneous tumor stroma remains a challenge. In this study, using GT198 as a marker, we provide critical evidence that breast tumor stromal cells in a reactive stroma are related in that they express cytoplasmic GT198 protein and share genetic mutations in the GT198 gene. More important, we show that mutant GT198 ${ }^{+}$ stromal cell populations are not homogeneous but distinct. Mutant GT198 ${ }^{+}$myoepithelial cells, adipocytes, fibroblasts, and their pericyte progenitors coexist. These cells potentially belong to related lineages of adipogenic, myogenic, or vascular smooth muscle cell origin. ${ }^{10}$ In a given tumor stroma, mutant descendants carrying the same mutation can be derived from precursor cells carrying the initial mutation, and together constitute a focal reactive tumor stroma (Figure 1E and Supplemental Figure S1). Not all stromal cells in a given tumor are altered or mutated. Mutant and normal stromal tissues can be juxtaposed. Thus, GT198 can be a useful marker to specifically distinguish mutant reactive tumor stromal cells from their normal counterparts.

A proposed hypothetical model of mutant GT198 is shown in Figure 6. It was established that perivascular cells, including capillary pericyte progenitors, are myogenic and adipogenic. ${ }^{10}$ These cells have the capacity to differentiate into adipocytes, stromal fibroblasts, and cells of vascular 
smooth muscle origin. ${ }^{9}$ Although a direct link between perivascular and myoepithelial cells has not been confirmed, both cell types are contractile and share a close functional relationship. Our findings on multiple lineages of mutant GT198 ${ }^{+}$stromal cells support this model, in which mutant myoepithelial cells, adipocytes, and stromal fibroblasts are potentially differentiated from mutant perivascular progenitors, such as capillary pericytes, together generating a mutant stroma as tumor microenvironment. In contrast, luminal epithelial cells may be descended from a divergent differentiation path than stromal cells, such that they are not directly affected by GT198 mutations but can still be promoted by molecular signaling from GT198 mutant stroma (Figure 6).

This altered breast cancer gene product in tumor stroma is potentially a logical marker for identification of cancer precursor lesions, because few cancer genes have been found to be extensively mutated in sporadic breast tumor stromal cells. Evidence supporting GT198 as a critical breast and ovarian cancer-inducing gene includes the presence of germline mutations in both breast and ovarian cancer families, ${ }^{26}$ recurrent somatic mutations in sporadic ovarian and fallopian tube cancers, ${ }^{28,29}$ and somatic mutations in breast cancer, as described in this study. In addition, GT198 is a critical DNA repair gene, ${ }^{24,37,38}$ regulating steroid hormone-mediated gene activation, ${ }^{21}$ and is located in a breast cancer gene locus at chromosome $17 \mathrm{q} 21 .{ }^{26}$ Together, these studies support that GT198 is a new marker to reveal mutant precursor lesions in human breast cancer.

Our findings are consistent with existing evidence on the importance of tumor stromal cells. Angiogenesis in tumor stroma and its occurrence before rapid tumor growth have long been recognized. ${ }^{34,39}$ Increased VEGF is considered central to angiogenesis. ${ }^{40}$ Antibodies against VEGF have been shown to be therapeutically effective. ${ }^{41}$ VEGF is also essential for angiogenesis in ovary because VEGF is associated with ovarian theca cells and the corpus luteum, ${ }^{42,43}$ where GT198 is expressed. ${ }^{29}$ In this study, our data show that mutant $\mathrm{GT} 198^{+}$pericytes in breast tumor stroma express VEGF (Figure 4A), and mutant GT198 protein induces VEGF expression (Figures $4 \mathrm{~B}$ and 5). In addition, mutant GT198 potently induced von Willebrand factor expression (Figure 5A), which is a critical factor in vascular homeostasis and angiogenesis, and its defect is associated with angiodysplasia. ${ }^{44,45}$ These results support that mutant GT198 in tumor stroma promotes tumor angiogenesis. Furthermore, adipogenesis is known to be induced by glucocorticoid receptor ligand dexamethasone, ${ }^{46}$ and GT198 is a glucocorticoid receptor coactivator stimulating dexamethasone-induced gene activation. ${ }^{21}$ Our data also show that mutant GT198 protein promotes the expression of several markers regulating adipogenesis, such as peroxisome proliferator-activated receptor $\gamma$, CCAAT-enhancer-binding protein $\alpha$, sterol regulatory element-binding protein 1 , and fatty acid synthase (Figure 5A) ${ }^{47}$ implicating a role of GT198 in meditating adipogenesis in breast cancer. Moreover, our finding on GT198 expression in myoepithelial cells is in agreement with the extensive observations of hormone-responsive myoepithelial cells in breast cancer initiation, ${ }^{4,6}$ and loss of myoepithelium as a hallmark of breast carcinoma in situ. ${ }^{1}$ Future studies on GT198 target genes and altered steroid hormone response in myoepithelial cells are needed, given that GT198 is a steroid hormone receptor coactivator. ${ }^{21}$

In summary, we have revealed mutant tumor stromal cells in human breast cancer using GT198 as a marker. Affected tumor stromal cell populations include myoepithelial cells, adipocytes, perivascular cells, capillary pericytes, and stromal fibroblasts. The mutant GT198 protein induces VEGF promoter and the expression of markers in angiogenesis and adipogenesis. We suggest that GT198 expression is a specific marker to define mutant reactive breast cancer stroma. GT198 has the potential to be a marker in early diagnosis and targeted treatment of human breast cancer.

\section{Acknowledgments}

We thank Kimberly K. Smith, Dr. Elizabeth J. Galbreath, and Linda M. Schirtzinger for their help on immunohistochemistry and Drs. Caixia Xi and Ali Arbab for materials and reagents.

\section{Supplemental Data}

Supplemental material for this article can be found at http://dx.doi.org/10.1016/j.ajpath.2016.01.006.

\section{References}

1. Moumen M, Chiche A, Cagnet S, Petit V, Raymond K, Faraldo MM, Deugnier MA, Glukhova MA: The mammary myoepithelial cell. Int J Dev Biol 2011, 55:763-771

2. Gudjonsson T, Adriance MC, Sternlicht MD, Petersen OW, Bissell MJ: Myoepithelial cells: their origin and function in breast morphogenesis and neoplasia. J Mammary Gland Biol Neoplasia 2005, $10: 261-272$

3. Richert MM, Schwertfeger KL, Ryder JW, Anderson SM: An atlas of mouse mammary gland development. J Mammary Gland Biol Neoplasia 2000, 5:227-241

4. Strum JM: Estrogen-induced alterations in the myoepithelial cells of the rat mammary gland. Cell Tissue Res 1978, 193:155-161

5. Brisken C, O'Malley B: Hormone action in the mammary gland. Cold Spring Harb Perspect Biol 2010, 2:a003178

6. Adriance MC, Inman JL, Petersen OW, Bissell MJ: Myoepithelial cells: good fences make good neighbors. Breast Cancer Res 2005, 7:190-197

7. Barsky SH, Karlin NJ: Mechanisms of disease: breast tumor pathogenesis and the role of the myoepithelial cell. Nat Clin Pract Oncol 2006, 3:138-151

8. Pandey PR, Saidou J, Watabe K: Role of myoepithelial cells in breast tumor progression. Front Biosci (Landmark Ed) 2011, 15:226-236

9. Armulik A, Genove G, Betsholtz C: Pericytes: developmental, physiological, and pathological perspectives, problems, and promises. Dev Cell 2011, 21:193-215

10. Crisan M, Yap S, Casteilla L, Chen CW, Corselli M, Park TS, Andriolo G, Sun B, Zheng B, Zhang L, Norotte C, Teng PN, Traas J, Schugar R, Deasy BM, Badylak S, Buhring HJ, Giacobino JP, Lazzari L, Huard J, Peault B: A perivascular origin for mesenchymal stem cells in multiple human organs. Cell Stem Cell 2008, 3:301-313 
11. Pietras K, Ostman A: Hallmarks of cancer: interactions with the tumor stroma. Exp Cell Res 2010, 316:1324-1331

12. Raza A, Franklin MJ, Dudek AZ: Pericytes and vessel maturation during tumor angiogenesis and metastasis. Am J Hematol 2010, 85: $593-598$

13. Bergers G, Song $\mathrm{S}$ : The role of pericytes in blood-vessel formation and maintenance. Neuro Oncol 2005, 7:452-464

14. Tang W, Zeve D, Suh JM, Bosnakovski D, Kyba M, Hammer RE, Tallquist MD, Graff JM: White fat progenitor cells reside in the adipose vasculature. Science 2008, 322:583-586

15. Kalluri R, Zeisberg M: Fibroblasts in cancer. Nat Rev Cancer 2006, 6: 392-401

16. Orimo A, Gupta PB, Sgroi DC, Arenzana-Seisdedos F, Delaunay T, Naeem R, Carey VJ, Richardson AL, Weinberg RA: Stromal fibroblasts present in invasive human breast carcinomas promote tumor growth and angiogenesis through elevated SDF-1/CXCL12 secretion. Cell 2005, 121:335-348

17. Hanahan D, Weinberg RA: Hallmarks of cancer: the next generation. Cell 2011, 144:646-674

18. Cao Y: Angiogenesis modulates adipogenesis and obesity. J Clin Invest 2007, 117:2362-2368

19. Menendez JA, Lupu R: Fatty acid synthase and the lipogenic phenotype in cancer pathogenesis. Nat Rev Cancer 2007, 7:763-777

20. Pandey PR, Xing F, Sharma S, Watabe M, Pai SK, Iiizumi-Gairani M, Fukuda K, Hirota S, Mo YY, Watabe K: Elevated lipogenesis in epithelial stem-like cell confers survival advantage in ductal carcinoma in situ of breast cancer. Oncogene 2013, 32:5111-5122

21. Ko L, Cardona GR, Henrion-Caude A, Chin WW: Identification and characterization of a tissue-specific coactivator, GT198, that interacts with the DNA-binding domains of nuclear receptors. Mol Cell Biol 2002, 22:357-369

22. Satoh T, Ishizuka T, Tomaru T, Yoshino S, Nakajima Y, Hashimoto K, Shibusawa N, Monden T, Yamada M, Mori M: Tat-binding protein-1 (TBP-1), an ATPase of $19 \mathrm{~S}$ regulatory particles of the $26 \mathrm{~S}$ proteasome, enhances androgen receptor function in cooperation with TBP-1interacting protein/Hop2. Endocrinology 2009, 150:3283-3290

23. Petukhova GV, Pezza RJ, Vanevski F, Ploquin M, Masson JY, Camerini-Otero RD: The Hop2 and Mnd1 proteins act in concert with Rad51 and Dmc1 in meiotic recombination. Nat Struct Mol Biol 2005, 12:449-453

24. Cho NW, Dilley RL, Lampson MA, Greenberg RA: Interchromosomal homology searches drive directional ALT telomere movement and synapsis. Cell 2014, 159:108-121

25. Enomoto R, Kinebuchi T, Sato M, Yagi H, Shibata T, Kurumizaka H, Yokoyama S: Positive role of the mammalian TBPIP/HOP2 protein in DMC1-mediated homologous pairing. J Biol Chem 2004, 279: 35263-35272

26. Peng M, Bakker JL, Dicioccio RA, Gille JJ, Zhao H, Odunsi K, Sucheston L, Jaafar L, Mivechi NF, Waisfisz Q, Ko L: Inactivating mutations in GT198 in familial and early-onset breast and ovarian cancers. Genes Cancer 2013, 4:15-25

27. Zangen D, Kaufman Y, Zeligson S, Perlberg S, Fridman H, Kanaan M, Abdulhadi-Atwan M, Abu Libdeh A, Gussow A, Kisslov I, Carmel L, Renbaum P, Levy-Lahad E: XX ovarian dysgenesis is caused by a PSMC3IP/HOP2 mutation that abolishes coactivation of estrogendriven transcription. Am J Hum Genet 2011, 89:572-579

28. Peng M, Yang Z, Zhang H, Jaafar L, Wang G, Liu M, Flores-Rozas H, Xu J, Mivechi NF, Ko L: GT198 splice variants display dominantnegative activities and are induced by inactivating mutations. Genes Cancer 2013, 4:26-38

29. Peng M, Zhang H, Jaafar L, Risinger J, Huang S, Mivechi NF, Ko L: Human ovarian cancer stroma contains luteinized theca cells harboring tumor suppressor gene GT198 mutations. J Biol Chem 2013, 288: 33387-33397

30. Sun D, Liu WJ, Guo K, Rusche JJ, Ebbinghaus S, Gokhale V, Hurley LH: The proximal promoter region of the human vascular endothelial growth factor gene has a G-quadruplex structure that can be targeted by G-quadruplex-interactive agents. Mol Cancer Ther 2008, 7 : 880-889

31. Conklin MW, Keely PJ: Why the stroma matters in breast cancer: insights into breast cancer patient outcomes through the examination of stromal biomarkers. Cell Adh Migr 2012, 6:249-260

32. Gangadhara S, Barrett-Lee P, Nicholson RI, Hiscox S: Pro-metastatic tumor-stroma interactions in breast cancer. Future Oncol 2012, 8: $1427-1442$

33. Viacava P, Naccarato AG, Bocci G, Fanelli G, Aretini P, Lonobile A, Evangelista G, Montruccoli G, Bevilacqua G: Angiogenesis and VEGF expression in pre-invasive lesions of the human breast. J Pathol 2004, 204:140-146

34. Ferrara N: VEGF and the quest for tumour angiogenesis factors. Nat Rev Cancer 2002, 2:795-803

35. Meiron M, Anunu R, Scheinman EJ, Hashmueli S, Levi BZ: New isoforms of VEGF are translated from alternative initiation CUG codons located in its 5'UTR. Biochem Biophys Res Commun 2001, 282: 1053-1060

36. Wen L, Chen LH, Li HY, Chang SP, Liao CY, Tsui KH, Sung YJ, Chao KC: Roles of estrogen and progesterone in endometrial hemodynamics and vascular endothelial growth factor production. J Chin Med Assoc 2009, 72:188-193

37. Pezza RJ, Voloshin ON, Vanevski F, Camerini-Otero RD: Hop2/Mnd1 acts on two critical steps in Dmc1-promoted homologous pairing. Genes Dev 2007, 21:1758-1766

38. Enomoto R, Kinebuchi T, Sato M, Yagi H, Kurumizaka H, Yokoyama S: Stimulation of DNA strand exchange by the human TBPIP/Hop2-Mnd1 complex. J Biol Chem 2006, 281:5575-5581

39. Fukumura D, Xavier R, Sugiura T, Chen Y, Park EC, Lu N, Selig M, Nielsen G, Taksir T, Jain RK, Seed B: Tumor induction of VEGF promoter activity in stromal cells. Cell 1998, 94:715-725

40. Roskoski R Jr: Vascular endothelial growth factor (VEGF) signaling in tumor progression. Crit Rev Oncol Hematol 2007, 62:179-213

41. Mortimer J, Zonder HB, Pal SK: Lessons learned from the bevacizumab experience. Cancer Control 2012, 19:309-316

42. Ferrara N, Chen H, Davis-Smyth T, Gerber HP, Nguyen TN, Peers D, Chisholm V, Hillan KJ, Schwall RH: Vascular endothelial growth factor is essential for corpus luteum angiogenesis. Nat Med 1998, 4: $336-340$

43. Kamat BR, Brown LF, Manseau EJ, Senger DR, Dvorak HF: Expression of vascular permeability factor/vascular endothelial growth factor by human granulosa and theca lutein cells. Role in corpus luteum development. Am J Pathol 1995, 146:157-165

44. Randi AM, Laffan MA, Starke RD: Von Willebrand factor, angiodysplasia and angiogenesis. Mediterr J Hematol Infect Dis 2013, 5: e2013060

45. Yang X, Sun HJ, Li ZR, Zhang H, Yang WJ, Ni B, Wu YZ: Gastric cancer-associated enhancement of von Willebrand factor is regulated by vascular endothelial growth factor and related to disease severity. BMC Cancer 2015, 15:80

46. Chapman AB, Knight DM, Ringold GM: Glucocorticoid regulation of adipocyte differentiation: hormonal triggering of the developmental program and induction of a differentiation-dependent gene. J Cell Biol 1985, 101:1227-1235

47. Peirce V, Carobbio S, Vidal-Puig A: The different shades of fat. Nature 2014, 510:76-83 